\title{
Vernacular Values in Architectural Heritage. The Case of Vale de Poldros
}

\author{
Anna Martynenko, Kharkiv National University of Civil Engineering and Architecture
}

\begin{abstract}
The article describes a traditional one-story building named cardenha, which is a type of vernacular building in the village of Vale de Poldros and widespread in the northern region of Portugal. The author has done the comparative analysis of construction of cardenha and similar structures that have dry stone masonry walls and corbelled dome roofs in the territory of the Mediterranean Basin. Related construction systems of cardenha were identified in the basic types of corbelled domes and unique features of the structures in Vale de Poldros are described.
\end{abstract}

Keywords - Cardenha, dry stone masonry, corbelled dome, basic types of corbelled domes.

\section{INTRODUCTION}

In our time, studies of the vernacular architecture of the world are not losing topicality. At the same time, there is a problem of preserving vernacular architecture, which is associated with the loss of traditional construction methods and technologies. There is a belief that the processes of globalization and urbanization in the world has negative impact on preserving the traditional architectural heritage. The reduction of rural population and fundamental change in lifestyle in villages has caused the disappearance conditions for the traditional architecture.

Cardenha, a traditional building typology of Portugal is an example of architectural heritage exposed to the risk of loss. Therefore, historians of architecture should document this kind of vernacular shelter in detail. Its construction techniques and methods, structural elements of construction, stages of building process, materials etc., should be depicted qualitatively to give a chance for future generation to build cardenha in a proper way. It is important to compare the cardenha structure with the traditional false-dome buildings in other countries around the world in order to find the most similar to cardenha types of buildings and to reveal its unique features. The goal of this research is to determine the cardenha structure in the existing typology of buildings with a false-dome.

\section{Methodology}

In the course of this study, the author applied such research methods as observation, modeling, and comparison. The method of comparative analysis was necessary to identify the similarities and differences between the structure of cardenha and other buildings with a false dome, to compare the construction methods, stages of building process, elements of false dome and its modifications.

\section{Discussion}

In the article the author relied on the studies of Professor M. Teixeira of the University of Lisbon about the traditional cardenha in the North of Portugal, presented in the book "Santo Antonio de Vale de Poldros" [1]. This book may help to find the right place of cardenha structure among the theoretical models of the false-dome systems around the world investigated by scientists. The author of this study used the theory of corbelled dome buildings typology developed by Professor Borut Juvanec of Faculty of Architecture in Ljubljana, as well as the research in the book "Corbelled Domes" [2] by German researcher Renate Lobbecke, who classified the structures with false dome into six basic types.

Over the last decade, the study of nonprofessional architecture has formed a special area of architectural discourse. This sphere of architectural theory deals with the structures of empirical building, constructed without involving a professional architect. "These include primitive or aboriginal architecture; indigenous architecture; ancestral or traditional architecture; folk, popular, or rural architecture; ethnic architecture or ethno-architecture; informal architecture; the so-called 'anonymous architecture' or 'architecture without architects'; and even 'non-pedigree' architecture" [3]. The number of vernacular buildings is significantly dominating over the constructions designed by professional architects. In 1991, the known researcher of vernacular architecture Amos Rapoport in his interview said: "We must not forget that architects design at most something like four or five percent of all buildings" [4].

Vernacular architecture is a significant part of the architectural heritage that reveals the richness of the world cultural diversity. The experience and knowledge of vernacular building art played a critical role in the history of architecture. Professor of Architecture Howard Davis of the University of Oregon in his book "The Culture of Building" [5] writes that building cultures are a worldwide global phenomenon. The scholar defines building cultures as complex systems of people, relationships, building types, techniques, and habits, in which design and building are anchored. Davis underlines the importance of the evolution of building cultures in general. He states that not only architects and city planners have impact on the building progress [5].

Nowadays, the study of nonprofessional architecture allows filling the gaps in the evolution of architecture, gives insight into the nature of concepts of shelter and dwelling, and reveals the significance of basic needs. Vernacular architecture stores the key knowledge on the essence of architectural form, typology 

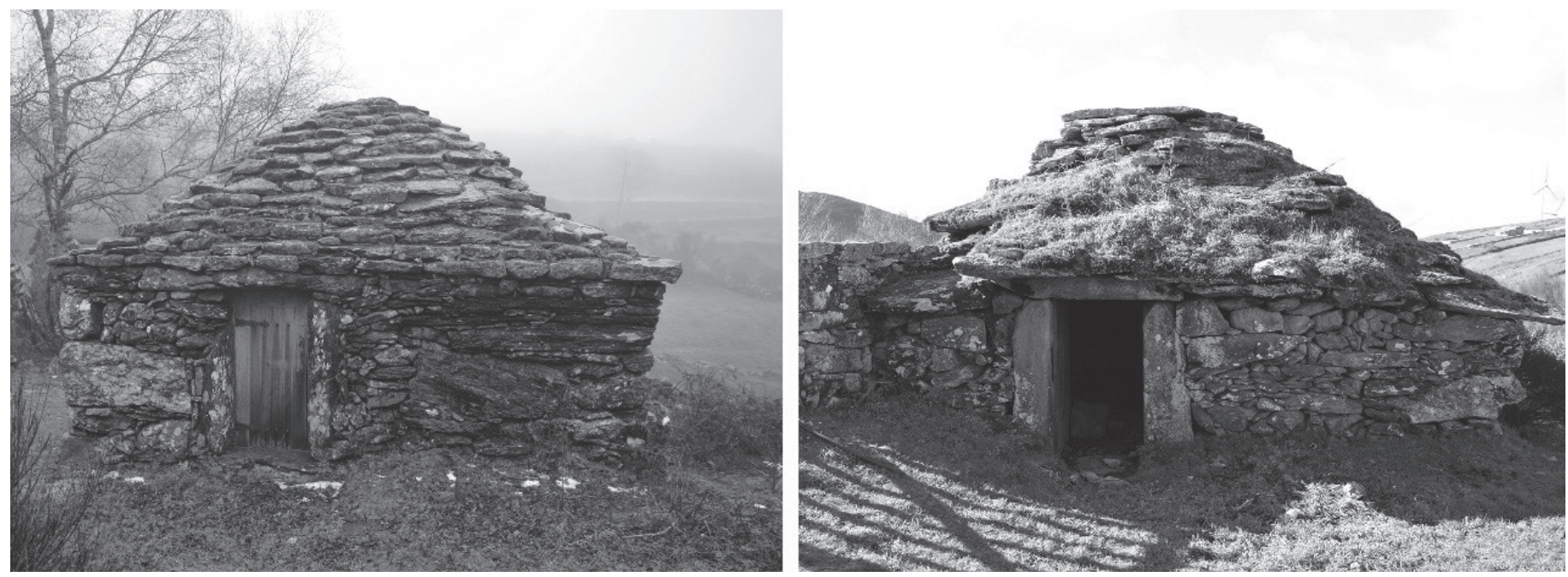

Fig. 1. Cardenha from Santo Antonio Val de Poldros [5].

of buildings and building processes; shows the links between knowledge and human activities. The first vernacular heritage scientist who emphasized the influence of social and cultural factors on the form of houses and constructions was Amos Rapoport. He presented his research in the book "House Form and Culture" [6]. The scientist believes that "the house form is not simply the result of physical forces or any single casual factor, but is the consequence of a whole range of socio-cultural factors seen in the broadest terms" [6]. Rapoport understands the traditional model of a house as "the result of collaboration of many people over many generations as well as the collaboration between makers and users of buildings and other artifacts" [6]. Climate and geographical conditions are reflected in vernacular architecture. Paul Oliver, Professor of Oxford Institute for Sustainable Development, states that one can lean on the methods of vernacular architecture when dealing with the important issue of adaptation to the environment. The wisdom of the generations of nonprofessional builders can ensure cultural and economic sustainability in a short span of time [7].

The investigation of nonprofessional architecture in Portuguese regions began in the middle of the 20th century. A special expedition to investigate Portuguese vernacular architecture was organized and financed by the government. Six teams of groups of 3 people divided the continental Portugal into 6 regions (Minho, Trás-os-Montes, Beiras, Estremadura, Alentejo, Algarve) - research zones. The collected material was published in the book "Arquitectura Popular em Portugal" [8]. The first volume appeared in 1961, the second - in 1980. The book drew a wide response in the Portuguese architectural society of the time. Since the book was published, scholars have made reappraisal of vernacular architecture and local building culture; identity was taken on a new level of demand. The book "Arquitectura Popular em Portugal" [8] attracted the attention of scientists to the quality of adaptivity and the ability to work with the terrain model. The concepts of space and comfort came to be regarded not only from the perspective of technological achievements, but also in terms of culture and psychology. Scientists started to encourage humane attitude of architects to the nearby constructions on the project site. The concept of the usefulness balance of a building and its control appeared. The concept was revealed in vernacular architecture in the quality of constancy and stability as well as in the changes of the external environment parameters (cultural and natural). Usefulness balance was a result of empirical economy of materials and technologies of many generations. Any innovations were introduced only due to paramount necessity or for a valid reason.

Presently, the investigation of unprofessional popular architecture in Portugal is still topical. International research project Versus (Vernacular Heritage Sustainable Architecture) was developed by the employees of Escola Superior Gallaecia Portugal (Portuguese higher education institution). The main purpose of the project is to replenish the arsenal of sustainable architecture with the strategies and principles found during the investigation of vernacular architecture in the territories of Portugal, Spain, France and Italy. The vernacular architecture of the northern Portugal differs from the vernacular architecture in the southern part of the county. For convenience, the border between the north and the south was drawn along the Tagus River. The relief north of the river is mostly mountainous, and there are flat hills and plains in the south. Such a division defined the typology of vernacular architecture. Stone (granite, shale) is mostly used in the north, whilst the main building materials in the southern part of the country are earth and straw. Wood is used along the coastline, in the plains rich with pinewood.

Cardenha is a unique type of Portuguese vernacular architecture found mostly in the northern part of Portugal (Fig. 1). Cardenha is a small shelter with a corbelled dome construction build with a dry stone method. This type of construction is investigated within the study of constructions and technologies of buildings of vernacular structures. Cardenha in Santo Anto- 

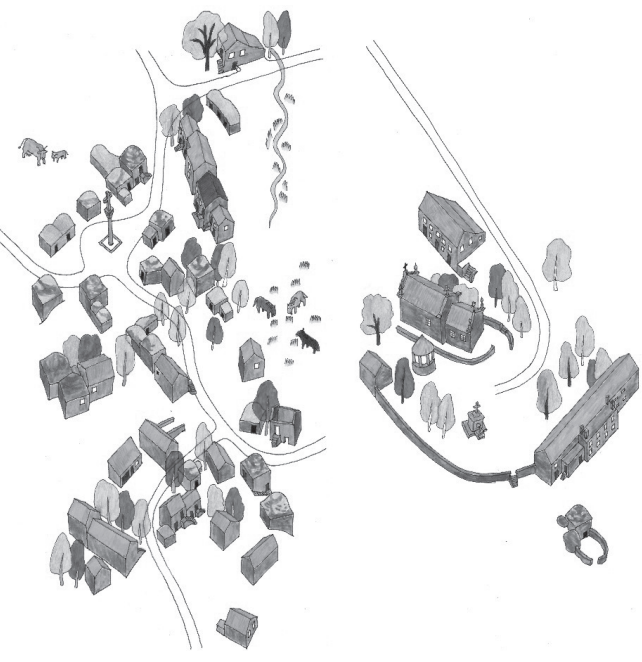

Fig. 2. Axonometry of Santo Antonio Valle de Poldros [5].
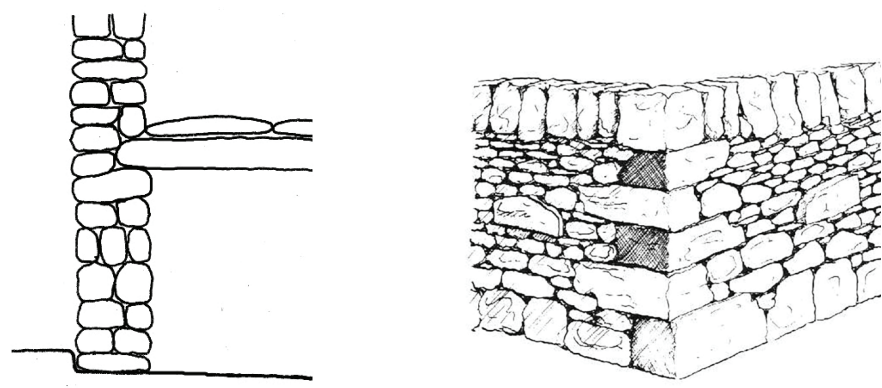

Fig. 4. Cross section of dry stone masonry cardenha wall [1].

Fig. 5. Construction of the corners in a dry stone masonry [9].
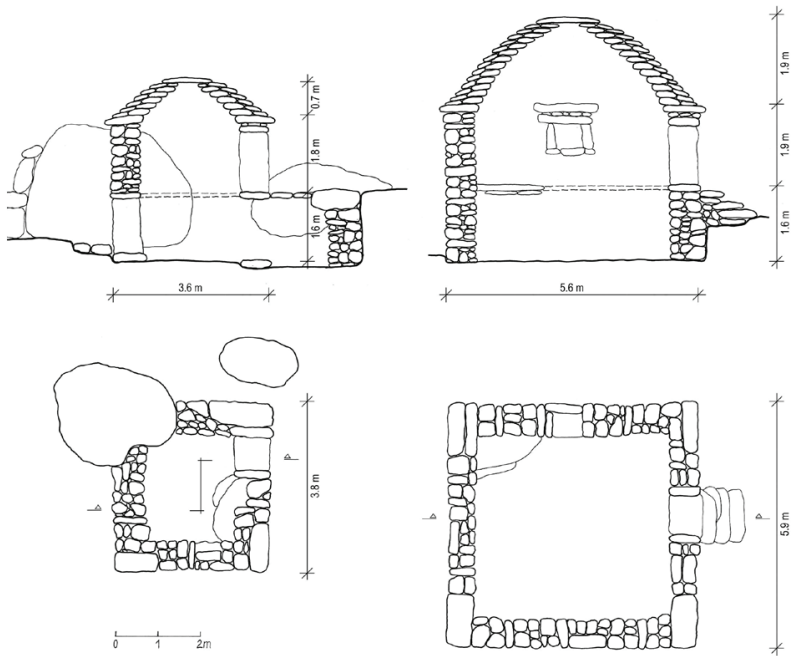

Fig. 3. The dimensions of the smallest and largest cardenha [5].

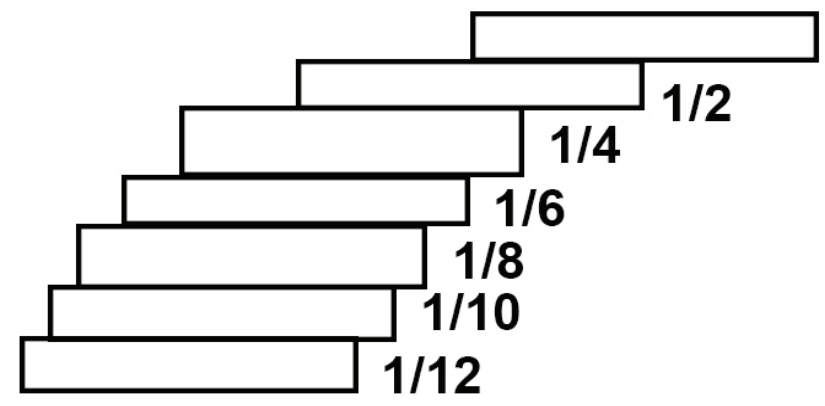

nio Val de Poldros of Minho province is described in this paper (Fig. 2). The aim of the research is to reveal the design properties of cardenha, its general volume and space character, the rules of location in landscape and in groups, and the characteristics of structural elements. It is highly important to locate the position of cardenha in the present system of the world classification of vernacular architecture constructions. The relief of Minho province is high and mountainous; it stretches to the north from the river of Douro. Santo Antonio Val de Poldros is located in Sierra-da-Peneda at the height of 1113 metres above sea level. Until the end of the 20th century, cardenha was used as a seasonal dwelling for summer time (between June and September) by rural people from the valley (Riba de Mouro, Tangil, Merufe) engaged in agriculture and cattle breeding [1].

People or domestic animals, which migrated from the valley to the mountains together with their masters for the hottest period of year, dwelled in such buildings. Cardenhas of different size and space are found in the territory of the settlement. They can be of one or two floors. The ground floor of a two-storey building was for domestic animals, the first floor - for people. Every floor of the house consisted of one room, the entrance to which was from outside. Cardenhas with two enfilade rooms on the ground floor were found in Santo Antonio Val de Poldros. In such cases, the far room was located on a hill. The buildings stand either separately or are united in groups by a stone wall, forming a yard. Sometimes, buildings have mutual walls. There are mostly buildings of square, rectangular or trapezoidal forms in the territory of Santo Antonio Val de Poldros. The examples of single-storey cardenha, the plan of which has roundish lines, can also be found. It is believed that the round cardenhas were built before quadrangular buildings. In two-storey buildings, one can enter the first floor by climbing the hill or walking up the stone stairs. The stairs are either integrated into the relief or detached.

In the smallest cardenha one side dimension of square plan is $3.8 \mathrm{~m}$ (Fig. 3). In the largest cardenha it reaches $5.9 \mathrm{~m}$ [1]. Each element is made of stones (mainly granite or schist) and arranged in a certain way. The physical parameters and properties of stones correspond to their position and function in the structural elements of cardenha. The size of stones can be very different: from $0.05 \mathrm{~m}$ to $2.50 \mathrm{~m}$ in length (Fig. 3). The construction of cardenha involves three elements: foundation, dry stone masonry of the walls and corbelled dome. For the construction of the walls of 


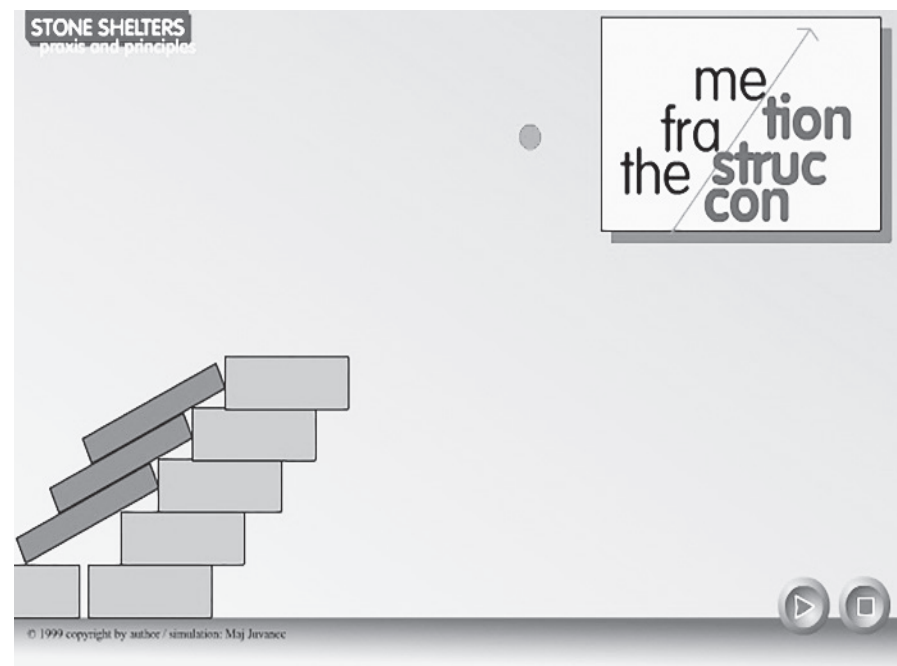

Fig. 7. The frame structure of corbelled dome [11].

cardenha a trench in the earth is prepared in advance. The width of the trench corresponds to the size of the wall. Foundation stones are placed in this deepening in earth (Fig. 4). Big slabs are chosen to build the base of the wall. The seams between the stones are arranged in a checkerboard pattern to distribute the load from one stone to (at least) two next stones that are located in the row below. This position of slabs helps to achieve a good compound between them and to reach general stability of the wall (Fig. 5).

Another important element of the dry stone wall is the stone which connects the two wall surfaces - the interior and exterior [1]. Average thickness of the wall is $0.75 \mathrm{~m}$.

The corner construction is arranged in a special way. Large long stones $(2.50 \mathrm{~m})$ are placed alternately each on another, so that each stone comes flush with the end surface of the wall perpendicular to it (Fig. 3). Additional elements of the wall structure are a doorway and a niche. The doorway is made of four elements: the stone of the threshold, two racks and lintel. The racks may consist of several stones. The average height of a doorway is $1.3 \mathrm{~m}$ and width is $0.7 \mathrm{~m}$. The width of these stones is equal to the width of the wall (about $0.75 \mathrm{~m}$ ). The threshold and the lintel stone have two holes, which are adapted to rotate the wooden door in it. The door opens towards inside of the room. The racks of the doorway have a protuberance for a more snug fit door [1].

The cornice finishes complete the wall structure by surrounding its perimeter. The cornice is made of long flat stones, which protrude from the plane of the wall by $0.2 \mathrm{~m}$. This protuberance reduces the quantity of moisture in the wall. The stones of cornice lay flat across the walls. It binds the double wall stones and distributes the load from the roof [1].

The construction of corbelled dome is a design feature of cardenha.

A corbelled dome, or false dome is different from a "true dome". The corbelled dome consists of purely horizontal layers, while in cupolas they perpendicularly follow the construction plane. As the layers get higher, each is slightly cantilevered, or

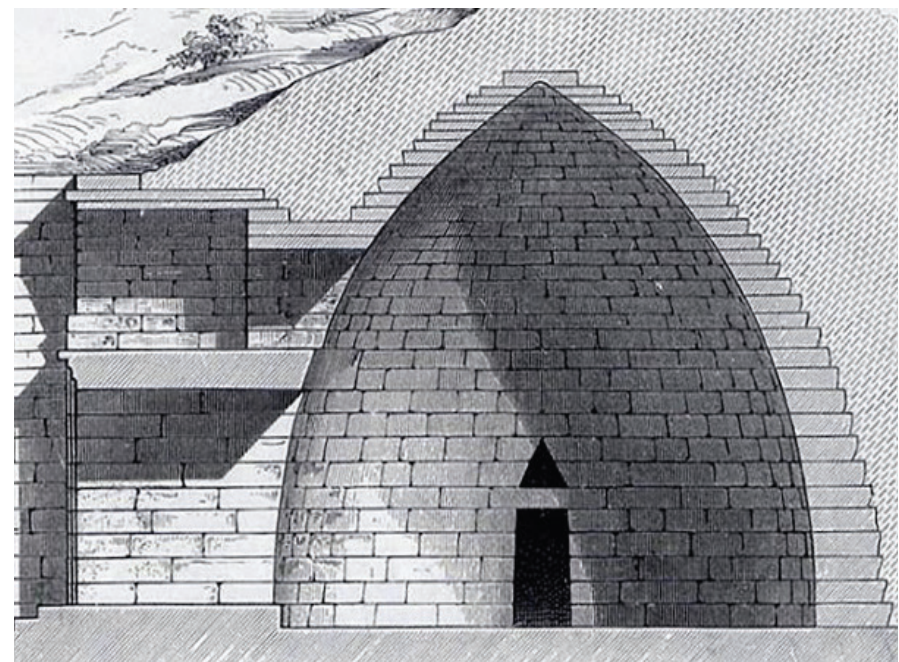

Fig. 8. Cross section of Mycenaean Treasury of Atreus (1250 BC) [12].

corbelled, toward the centre until meeting at the top (Fig. 6), (Fig. 7). The false dome is "in principle a planar construction overhanging in section" [10]. There are two layers in the composition of corbelling construction: "the inner is the object's construction, and the outer is the counter weight, frame and cover setting in one" [11].

The building technology of corbelled dome is one on the most ancient in the world that has survived until nowadays. The first constructions were used in the sacred architecture of the past. In buildings like underground temples, tumuli, beehive tombs, treasuries, the earth mound works as a cantilevered weight and helps to properly distribute the load in the false dome. There are numbers of ancient underground monuments, such as temple Hal Saflieni (dating back in 4000 BC) in Malta, the tumuli Newgrange in Ireland (built from 3000 BC to 2500 BC) and the Mycenaean Treasury of Atreus (1250 BC) (Fig. 8), (Fig. 9). The historians believe that the first example of ground-based structures with corbelled dome are megalithic temple complex Hagar Qim (3600-3200 BC) in Malta and the chamber tomb Naveta in the Balearic island of Minorca (early Bronze Age).

The military systems in the Nuraghi culture of Sardinia (from 2300 to $500 \mathrm{BC}$ ) are also keeping secrets of corbelled constructions [14]. The identities of places, materials and individuality of builders created a wide variety of corbelled constructions in different countries of the world, which are unified by a single logic of structure (Fig. 10). Massimo Leserri, in his article "Dry stone architectures, a problematic survey" writes: "The construction process of dry wall structures is characterised by the identity of the places because the worksite is also an extraction, transformation and construction location; identity of materials because the stone is the only building material used; identity of the builder because he/she is the same person who gathers the material and builds the structure" [15].

The main zone with buildings of this particular building structure is located in the territory of Mediterranean Basin. In the 


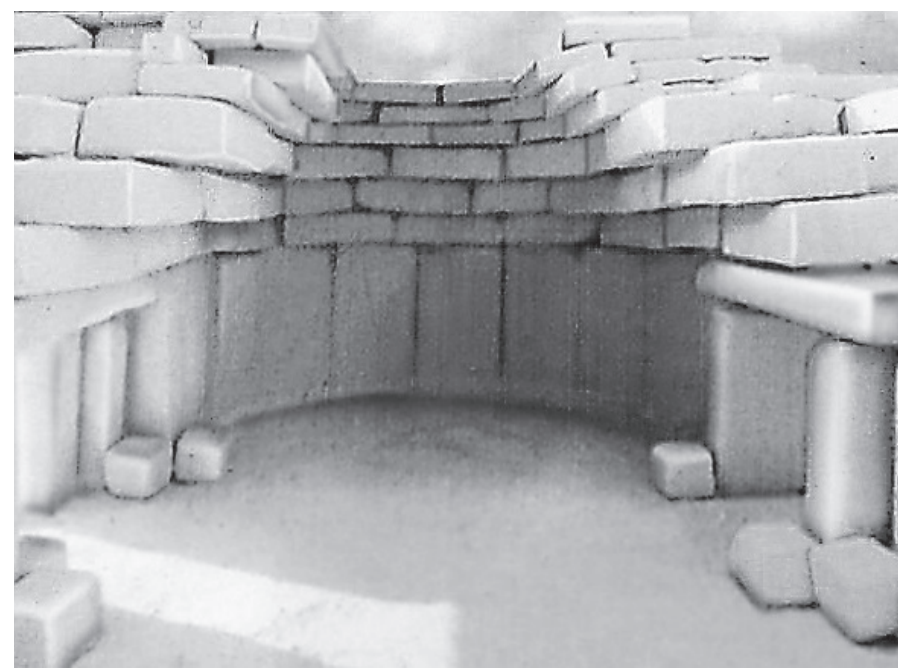

Fig. 9. Reconstruction of the north temple roof of megalithic temple complex Hagar Qim (3600-3200 BC), Malta [13]

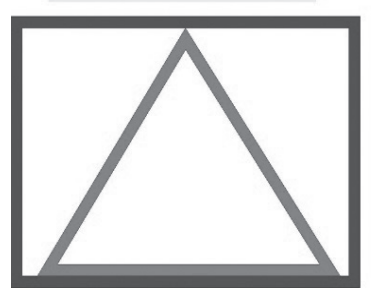

frame

\section{construction}

Fig. 11. Three elements of corbelled construction: vaulting itself (construction), frame (facing), filler (infilling) [10].

Italian regions of Apulia, Sicily, Sardinia and Liguria, the dry stone huts are widely distributed. There are a lot of this kind of structures in the western region of Croatian coast, southern areas of France and most lands of Spain including the Balearic Islands. They can be found in some regions of Scotland and Ireland in more rare cases [16].

One of the first scientific descriptions of false domes and dry stone structures was given by Emile Bertaux in article "Etude d'un Type d'Habitation Primitive. Trulli, caselle et specchie des pouilles" published in in 1899 [17].

Professor Borut Juvanec of the Faculty of Architecture in Ljubljana is a specialist, expert and theorist of buildings with a false arch. The scientist collects the typologies of vernacular buildings with drywall constructions around the world. He studied and described more than 18 kinds of structures: cabane (which has many local names in different places all over in France); hiška (shelter in Karst region, mostly in Slovenia); girna (most examples of shelters in Malta); trullo (built singly, in clusters, or forms towns in Puglia, Italy); kažun (a structure in the Istrian peninsula); clochan (still used for sheltering sheep and goats, located in the Dingle peninsula in Ireland), barraca de vinya (buildings in Catalonia, can be found from Valencia to further south or in the middle of Spain), and other [18]. The main hypothesis of Borut

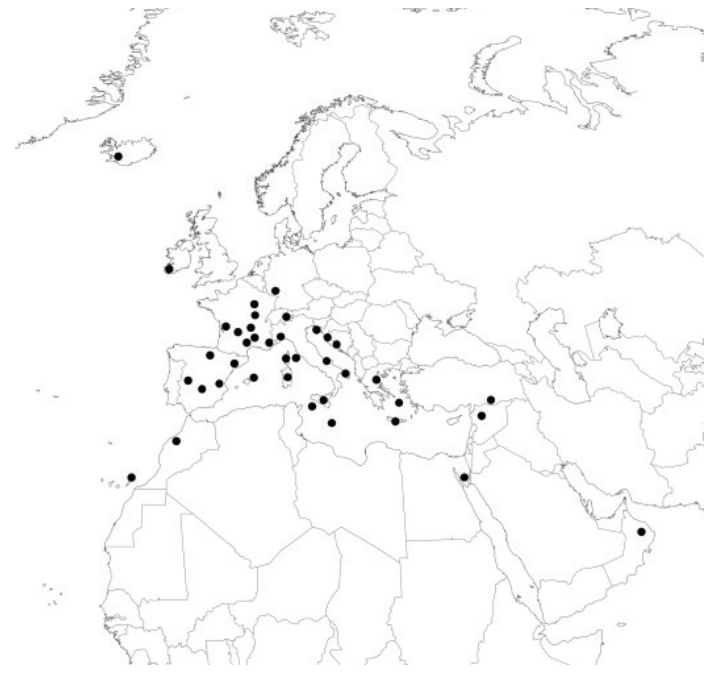

Fig. 10. Location of corbelled dome constructions in the world [15].
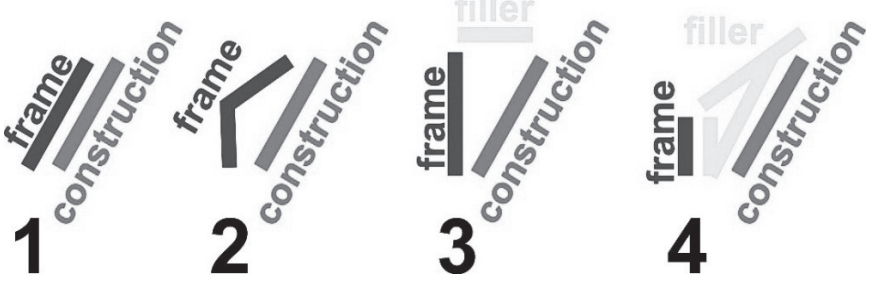

Fig. 12. Variants of the position of the three elements in a false dome [10].

Juvanec is: "The stone shelters are the most modest architecture man ever made. The main purposes are: taking off the stone from the field, protection for the man, livestock and the food as well as the tools. Constructional principle is corbelling; drywalling system. The stone shelter is a small, simple construction, but brilliant architecture, close to the man and his needs, and the point is: it is the pure culture, indeed" [18].

According to Borut Juvanec's theory, corbelled constructions have some types of interaction of the three components (Fig. 11). "First, there is the corbelled vault proper, theoretically circular in plan. Then, there is the facing or revetment, made of big stones. Finally, the infill thrown in between the two skins (corbelling and revetment) or over the roof. The infill can be waste stone from cutting, or fine stone rubble. Of course this solution is possible only in areas with little rain" [10]. In some cases, lot of large stones can crown the top. Borut Juvanec defines the typology of buildings with corbelled dome by the location of these three elements in construction.

In the schematic way the scientist describes the possible positions of the three elements in a corbelled dome (Fig. 12). Double-skin construction is the name of the first scheme built of hewn stones (Fig. 12, 1). In this case, the outside structural layer repeats the curve of inside structural layer. Double-skin con- 


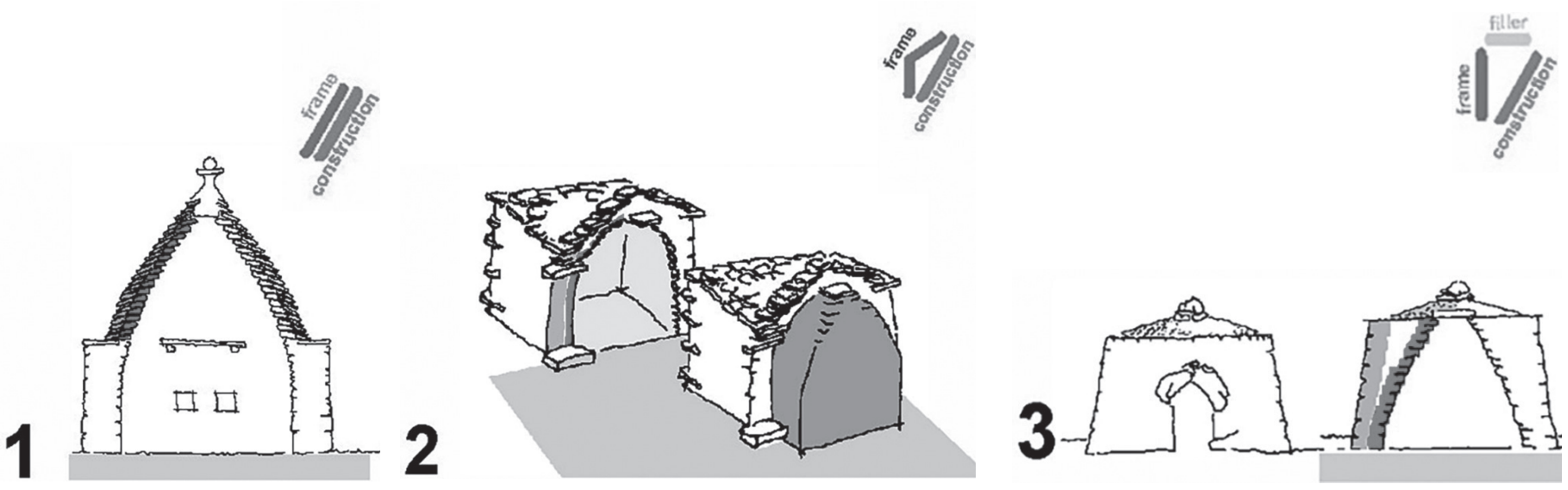

Fig. 13. A trullo, near Alberobello, Pu- Fig. 14. A pagliaddiu at Santu Pietru, Corsica (France) [10]. Fig. 15. A girna in Mistra Valley, Malta [10]. glia, Italy [10].

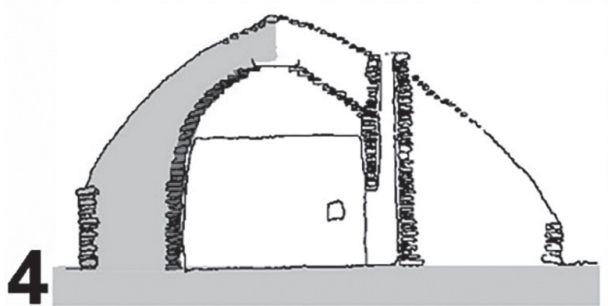

Fig. 16. A bombo near Tomelloso (Central Spain) [10].

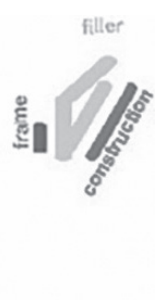

Fig. 17. A cardenha from Santo Antonio Val de Poldros [1].

TABLE I

Basic Types of Corbelled Domes [2]

\begin{tabular}{|l|l|l|}
\hline Basic Types \\
\hline $\begin{array}{l}\text { Type } 1 \\
\text { The exterior shape corresponds to the inner dome } \\
\text { layer. }\end{array}$
\end{tabular}

struction is common in the trullo of southern Italy, and in Switzerland (Fig. 13).

If there is a space between the layers of revetment and corbelled vault, it is filled with small stones or rubble. In France, the pagliaddiu structures in Corsica have such feature, described by Borut Juvanec in Fig. 12 and Fig. 14.

The Corsican pagliaddiu corbelling structure leans against the vertical walls at shoulder height. The stones are laid in a vertical 
Type 1

Type 2
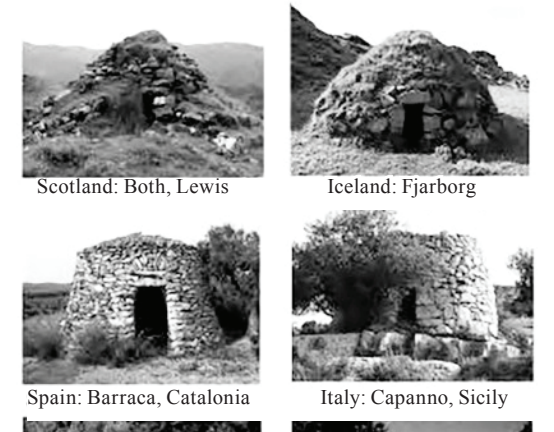

Type 4
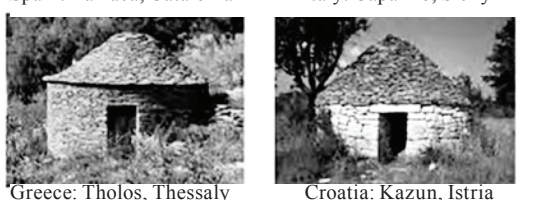

Type 5
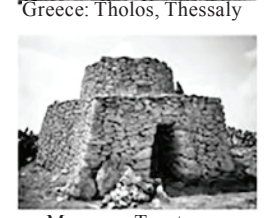

Type 6
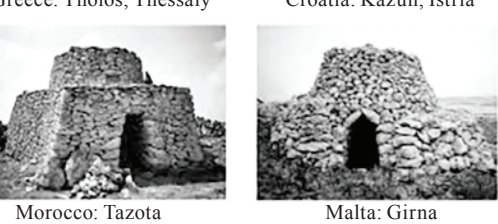

Malta: Girna

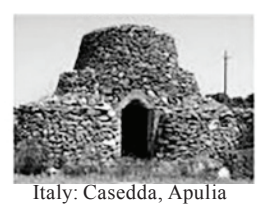

Spain: Barraca de bestiar, Minora

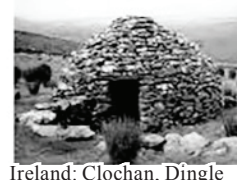

Ireland: Clochan, Dingle

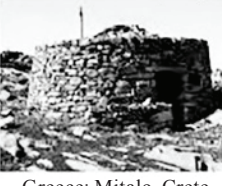

Greece: Mitalo, Crete
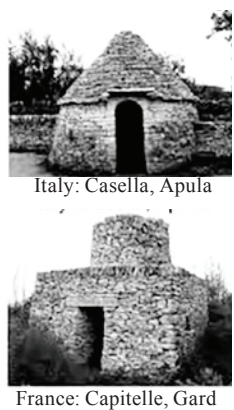

France: Capitelle, Gard

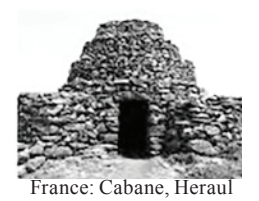

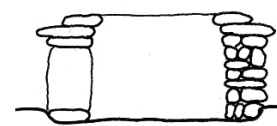
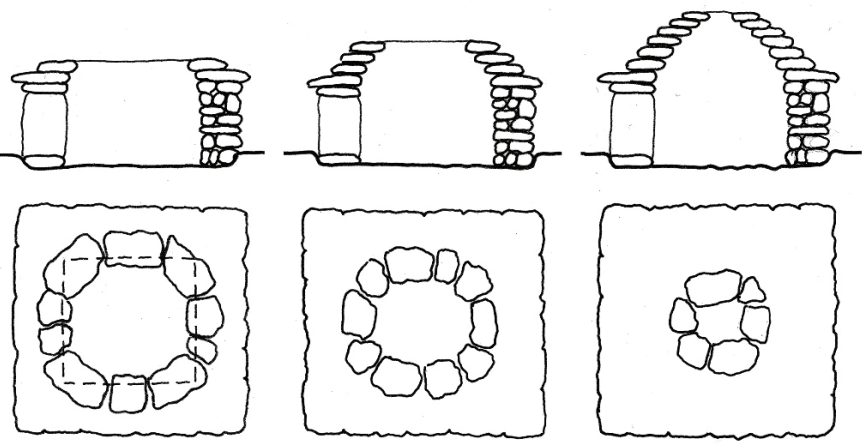

Fig. 19. The false dome constructing stages of cardenha in section [1].

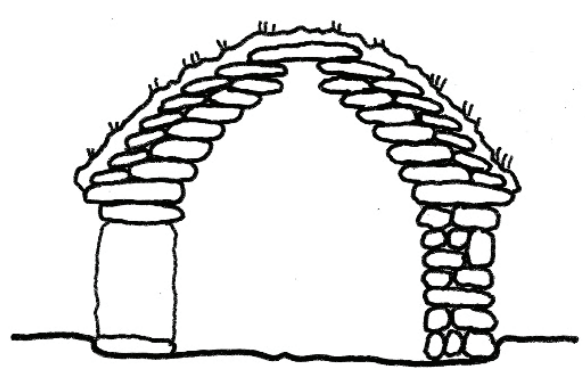

Fig. 20. The section of cardenha [1].

The wall structure of Portuguese cardenha is distinctly separated from the corbelled dome by cornice stone (Fig. 17). The corbel arch is above the cornice. The wall structure is strictly perpendicular to the ground and has equal dimensions throughout the height.

Cardenha in Portugal (Fig. 17) is very similar to trullo in Italy (Fig. 13) because its corbelled dome also has a double-skin construction. However, unlike in trullo, stones in cardenha are not hewed, and structural stones are bigger than the stones of facing. In cardenha the structure of corbelled dome has the shape of a catenary curve in section which is different from the trullo shape.

Trullo represents a form from a simple cone to truncated pyramid. From above the roof of cardenha is covered by a layer of earth with grass that is similar to the pagliaddiu in Corsica in France. Renate Lobbecke is a German researcher of vernacular architecture specializing in the unique dry stone constructions and false dome. In her book "Corbelled Domes" she describes the objects which she had been tracking down for 25 years in around 15 countries and in more than 50 regions. The researcher conducted comparative studies of false domes around the world and classified them into six basic types. In Renate Lobbecke's classification system cardenha is closer to the forth kind of basic types of corbelled cupolas. "The roof is distinctly set off above a vertical base zone" [2] in the buildings of Type 4 (Table I). Tho- 


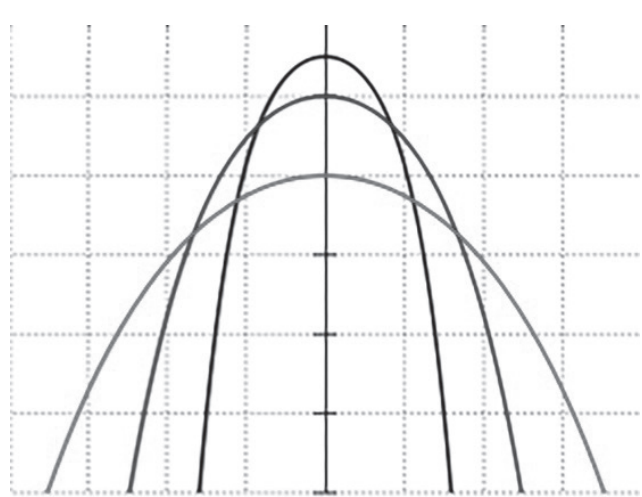

Fig. 21. The curve of catenary [1].

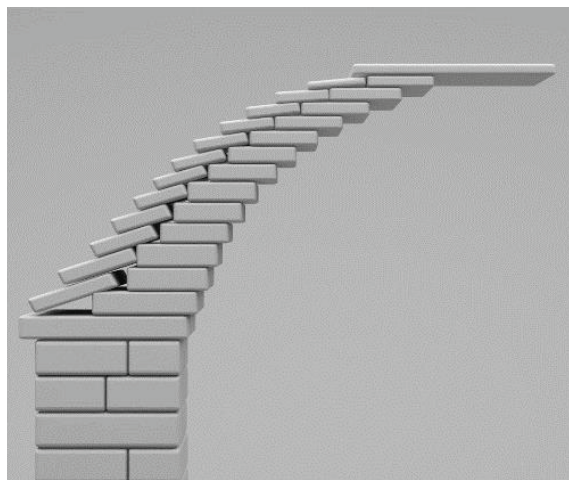

Fig. 22. The section of cardenha false cupola [Picture: A.Martynenko]

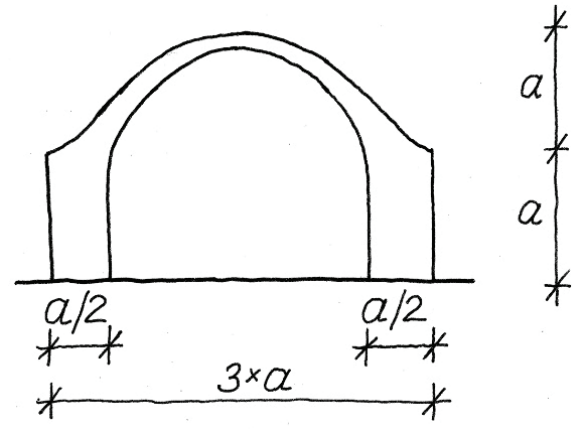

Fig. 23. The idea of proportional regularities of cardenha [1]. los in Thessaly in Greece, kazun in Istria in Croatia and casella in Apulia in Italy belong to Type 4. Cardenha looks like tholos in Greece (Fig. 18).

It also has a strongly marked cornice. The facades of both buildings have a strongly marked cornice between the structure of the wall and false dome. Their walls are perpendicular to the ground base. The difficulty of cardenha building technique is in the transition from the structure of a square shape of walls to the circle of cupola construction in horizontal cross section (plan). To deal with this task the intermediate shape of octagon is used. When the cornice is finished, the corbelled cupola starts from the first row in octagon shape. For this, four big flat slabs $(2 \mathrm{~m})$ are put on the places where walls meet in the corners. Each slab is placed on two walls so that the slab centre has overhang. The gaps between the corner rocks are filled with smaller rocks to form an octagonal perimeter of the first row in the false dome. Next rows of stones are placed in successively smaller concentric circles [1].

To build a cupola flat stones are used. The way of constructing a dome in cardenha is to use a "double skin" method, in which the stones of corbelled vaulting are placed horizontally and the stones of cladding are established in an angle of 15 degrees (Fig. 19), (Fig. 20). This slope of external layer contributes to a better trickling of water from the roof surface, and protects an interior from getting wet in the heavy rainfall in the northern region of Portugal [1].

In the vertical cross sectional line of false dome the construction (catenary) is formed by the fact that the distance of stone shear grows closer to the apex of the dome (Fig. 21), (Fig. 22). There are certain ideas of shape and volume regularity in cardenha that were developed in analytic way.

In the book "Santo Antonio Val de Poldros", some proportional rules of cardenha are described by Professor Manuel C. Texeira (Fig. 23). They are as follows: If "a" is the height of the wall (ranging from $1.1 \mathrm{~m}$ to $1.7 \mathrm{~m}$ ), then the height of the false dome is the same size. Cardenha's plan tends to be a square the side of which is equal to triple "a" from outside, and the thickness of the wall is half of "a" [1].
Thus, in the case where the height of the wall is equal to $1.50 \mathrm{~m}$, the height of the false cupola will also be $1.50 \mathrm{~m}$.

The general height of the building will be $3.00 \mathrm{~m}$. The width of walls will be equal to $0.75 \mathrm{~m}$. Both sides of cardenha plan will be the same size and will be equal to $4.50 \mathrm{~m}$ from outside and $3.00 \mathrm{~m}$ from inside.

\section{Conclusion}

Thus, cardenha is similar to the other buildings of the Mediterranean basin that have a false vault construction but also has its own unique qualities caused by the identity of natural conditions and materials and power of local traditions. Cardenha has some distinctive features: the wall structure is strictly perpendicular to the ground and separated from the corbelled cupola by cornice stones; the corbel arch starts above the cornice; the wall structure has equal dimensions throughout the height. The construction of cardenha in Portugal is very similar to trullo in Italy because its corbelled dome also has a double-skin construction. According to Renate Lobbecke's classification system cardenha is closer to Type 4 of basic corbelled cupola types.

\section{REFERENCES}

1. Teixeira, M. C. Santo Antonio de Vale de Poldros. Moncao: Sersilito-empresa grafica, Lda., 2016, 184 p.

2. Lobbecke, R. Corbelled Domes. Köln: Walther König, 2013. 384 p. ISBN13: 9783-8633-52745

3. Arboleda, G. What is Vernacular Architecture? [online]. Ethno Architecture [cited 20.05.2016]. http://www.vernaculararchitecture.com/\# ftnref1

4. Noschis, K. (ed.). Interview with Amos Rapoport. Architecture \& Comportement / Architecture \& Behaviour, Federal Institute of Technology Lausanne, Switzerland. 1992, Vol. 8, No. 1, pp. 93-102.

5. Davis, H. The Culture of Building. New York, NY: Oxford University Press, 2006, 400 p. ISBN-13: 978-0195305937

6. Rapoport, A. House form and culture. Englewood Cliffs, NJ: Prentice Hall, 1969, 146 p. ISBN-13: 9780133956733

7. Oliver, P. (ed.). Encyclopedia of Vernacular Architecture of the World, Vol. 1, Cambridge: Cambridge University Press, 1997, 833 p.

8. Távora, F., Pimentel, R., Menéres, A., Filgueiras, O. L., Araújo, A., Dias, C. C., Keil do Amaral, F., Lobo, J. H., Malato, J. J., Pereira N. T., Pinto de Freitas, A., Dias, F. S., George, F., Gomes, A. A., 
Antunes, A. M., Martins A. P., Celestino de Castro, Torres, F. Arquitectura Popular em Portugal. Publisher: Ordem dos Arquitectos, 4th edition, 2004, 440 p. ISBN: 9789729766879

9. Construction of the corners in a dry stone masonry : Technical Specifications for Dry Stone Walls [online]. Dry Stone Walling Association of Great Britain [cited 19.06.2012]. http://www.dswa.org.uk/

10. Juvanec, B. Vaulting, facing and infilling as components of corbelled construction [online]. VASSA Journal, No. 17, June 2007, pp. 8-12. ISSN: 1562-5257 [cited 28.05.2016]. http://www.vassa.org.za/wp-content/ uploads/2011/01/VASSAJrnl17-compressed.pdf

11. Juvanec, B. "Stone Shelters" [online]. Internet project [cited 13.04.2016]. http://www2.arnes.si/aa/shelters/

12. Section of Mycenaean Treasury of Atreus (1250 BC) [online]. blogger.com [cited: 28.09.2014]. http://4.bp.blogspot.com/-w3eTF4EQjIY/VChiOVIEXjI/AAAAAAAAfUw/Z6MQeiYVfGs/s1600/tesoro-atreo.jpg

13. Reconstruction of the north temple roof of megalithic temple complex Hagar Qim (3600-3200 BC) Malta [online]. Wikipedia [cited: 07.05.2016]. https://commons.wikimedia.org/wiki/File:Couverture_du_temple_Hagar_ Qim.jpg?uselang=fr

14. Juvanec, B. Hut of Extremadura : Jewel in Stone $=$ Chozo de Extremad ura : Joya en Piedra. Extremadura: Arte, 2008, 120 p. ISBN 978-84-612 1956-8

15. Leserri, M., Rossi, G. Dry stone architectures, a problematic survey [online]. EGA. Revista de expresión gráfica arquitectónica [S.1.], No. 22 Nov. 2013, pp. 184-195. ISSN 2254-623 [cited 21.05.2016.]. http://polipapers.upv.es/index.php/EGA/article/view/1532

16. Ambrosi, A. L'architettura in pietra a secco : costruzioni, progetto, tipologie, in "Architettura in pietra a secco". Atti del 1 Seminario Internazionale, Noci-Alberobello, 27-30 settembre 1987, Schena Editore, Fasano.

17. Bertaux, E. Etude d'un Type d'Habitation Primitive. Trulli, caselle et specchie des pouilles. Annales de Géographie. Année 1899, Vol. 8, No. 39 pp. 207-230

18. Juvanec, B. Shelters in stone, research work, short version. Ljubljana University Editions, Ljubljana, 2001. ISBN 961-6410-00-8

19. Lobbecke, R. Corbelled Dome: Outer Hebrides, Scotland [online, cited 31.05.2016]. http://www.renateloebbecke.de/Corbelled_Domes/Corbelled_ Domes files/Loebbecke,Outer\%20Hebrides.pdf

20. Veiga de Oliveira, E., Galhano, F., Pereira, B. Construções Primitivas em Portugal. Lisboa: Publicações Dom Quixote, 1994. 363 p. ISBN: 9722 0019-65 97-8972-2001-960
21. Juvanec, B. Six Thousand Years of Corbelling, UNESCO Congress, Paris, 2001, 7 p

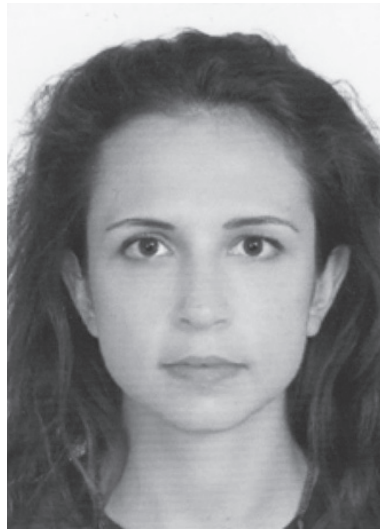

Anna Martynenko received the degree of Bachelor of Architecture (Architecture of Building and Structures) from the Faculty of Architecture of Kharkiv National University of Civil Engineering and Architecture, Ukraine, in 2010. She received the Diploma of Specialist in Architecture (Architecture of Building and Structures) from the Faculty of Architecture of Kharkiv National University of Civil Engineering and Architecture, Ukraine, in 2011. From 2013 to 2016, she was a doctoral student with the Faculty of Architecture of Kharkiv National University of Civil Engineering and Architecture, Ukraine. From 2015 to 2016, she participated in Erasmus Mundus exchange programme INFINITY in Faculdade de $\mathrm{Ar}$ quiteturain of Universidade de Lisboa, Portugal, carrying out the research for her thesis.

The topic of her doctoral thesis is "Transmission of Vernacular Architecture Language in Contemporary Architectural Design".

She is currently an Assistant Professor with the Chair of Achitectural Fundamentals of Kharkiv National University of Civil Engineering and Architecture in Ukraine.

\section{Contact Data}

\section{Anna Martynenko}

Kharkiv National University of Civil Engineering and Architecture Address: 40 Sumska St., Kharkiv, 61002, Ukraine

E-mail: annamartinenko2012@gmail.com 